University of Zurich

Department of Economics

Working Paper Series

ISSN 1664-7041 (print)

ISSN 1664-705X (online)

Working Paper No. 324

\title{
Unemployment and the Demand for Money
}

Samuel Huber, Jaehong Kim and Alessandro Marchesiani

May 2019 


\title{
Unemployment and the Demand for Money*
}

\author{
Samuel Huber \\ University of Basel
}

\author{
Jaehong Kim \\ Xiamen University
}

May 25, 2019

\author{
Alessandro Marchesiani \\ University of Liverpool
}

\begin{abstract}
We develop a dynamic general equilibrium model to analyze the relationship between monetary policy, money demand, and unemployment. Our model succeeds in replicating the empirical fact of a downward sloping Phillips curve for low inflation rates and an upward sloping curve for high inflation rates. The reason is that low inflation rates make saving, as opposed to consumption, more attractive. Less consumption is associated with less output and therefore higher unemployment. To the contrary, when inflation exceeds a certain threshold, money is too costly to hold, which results in a decrease in output and an increase in unemployment.
\end{abstract}

Keywords: Money, inflation, overlapping generations, unemployment. JEL Classification: D90, E31, E41, E50.

\section{Introduction}

It is well understood among economists that money demand and nominal interest rates are in a stable negative relationship in the long-run. ${ }^{1}$ There is less agreement, however, about the long-run relationship between nominal interest rates and unemployment. In Figure 1, we show

\footnotetext{
* Samuel Huber is a research fellow at the Department of Economic Theory, University of Basel. E-mail: samuel_h@gmx.ch. Jaehong Kim is an associate professor at the Wang Yanan Institute for Studies in Economics and the School of Economics, Xiamen University. E-mail: jaehongkim@xmu.edu.cn. Alessandro Marchesiani is a reader in economics at the University of Liverpool. E-mail: marchesiani@gmail.com.

${ }^{1}$ The negative relationship between nominal interest rates and money demand is well documented by Lucas (2000). Some studies have shown that financial innovations and technological advances cause instabilities in this relationship. However, some others have also shown that, when correcting for these circumstances, the relationship remains stable. For these studies, we refer to Lucas and Nicolini (2015).
} 
the dynamics of the unemployment rate and the nominal interest rates in the period 1959-2018 for the United States. ${ }^{2}$ A negative relationship is observed before the 1960s and after the 1990s, while in between the opposite seems to hold. As both periods with a downward sloping Phillips curve are characterized by rather low nominal interest rates, we conjecture that this relationship is convex in the long-run, which is evident when having a look at the trend time series shown in Figure 2. ${ }^{3}$



Figure 1: U.S. UNEMPLOYMENT AND INTEREST RATES: 1959 - 2018

The aim of this paper is to develop a microfounded monetary model able to explain the negative relationship between money demand and nominal interest rates, as well as the convex relationship between nominal interest rates and unemployment. We do so by integrating an overlapping generations (OG, hereafter) structure into the standard Lagos and Wright (2005) setup.

Although we discuss unemployment extensively in the paper, we want to emphasize from the

\footnotetext{
${ }^{2}$ For the calculation of the trend time series, we apply the Hodrick-Prescott filter with a value of $\lambda=1600$.

${ }^{3}$ To be precise, the Phillips curve refers to the empirical relationship between inflation and unemployment. In our model, however, inflation is one-to-one related to the nominal interest rate, due to the Fisher equation, so with a slight change in the description, we use inflation and interest rate interchangeably. For clarity, Table 2 shows the unemployment rate (raw unemployment, trend unemployment and model unemployment) vs the trend interest rate.
} 
beginning that our model does not provide a theory of the labor market (and so unemployment). Instead, we assume the stability of Okun's Law which describes the empirical relationship between output and unemployment. This "short-cut" allows us to establish a link between inflation and unemployment, and so to focus on the Phillips curve, while keeping the model simple. In particular, we obtain a downward sloping Phillips curve for low nominal interest rates and an upward sloping curve for high nominal interest rates, as shown in Figure 2. We show that this approach significantly improves the combined fit of money demand and unemployment when compared with previous studies.

While we recognize the importance of having an integrated theory of money and unemployment when discussing the Phillips curve, we believe that our approach has some advantages since the negative empirical relationship between output and unemployment is stable in the long-run. Okun's Law is also consistent with some of the most used theories of unemployment (e.g. Mortensen and Pissarides, 1994; Rogerson, 1988). Therefore, we think that nesting a specific theory of unemployment in the model will generally not affect the results much, while it may unnecessarily complicate the analysis. Also, our approach eliminates the discretion about what theory of unemployment to use, and it can be compared to other studies on money and unemployment.

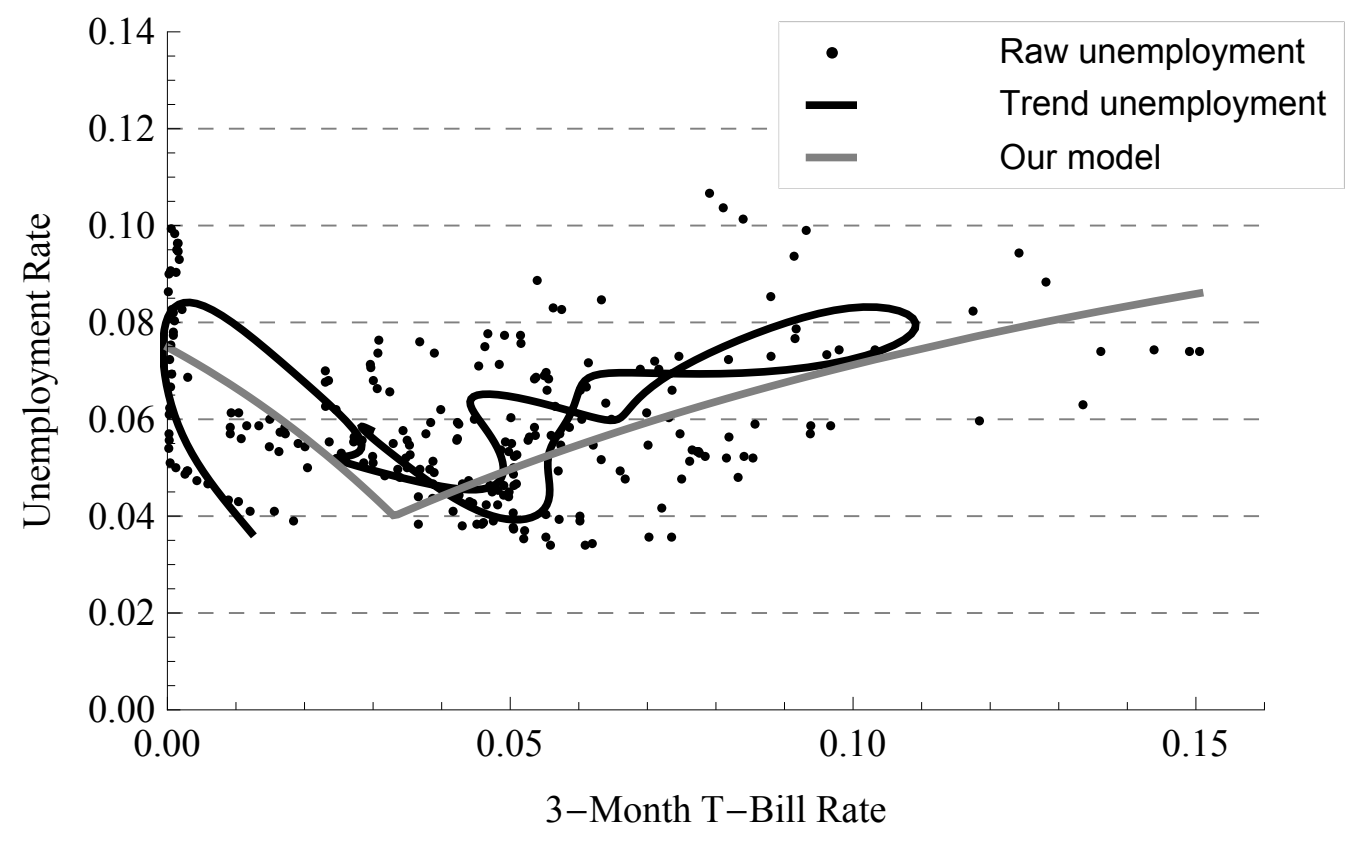

Figure 2: Performance of OUR MOdel 
In the model, agents earn a high wage when young. When nominal interest rates are low, their consumption is low and precautionary savings for retirement are high. This reduces overall economic activity and, presumably, increases unemployment. For intermediate nominal interest rates, agents consume more and save less when they are young, which increases output and reduces unemployment. When nominal interest rates increase further above a given threshold, the benefit from saving disappears and the negative effect of the inflation tax dominates. Hence, in such an environment higher nominal interest rates are harmful to the overall economic activity and result in an increase in unemployment, which may explain why we observe an upward sloping Phillips curve. ${ }^{4}$

\section{Literature Review}

This paper is related to the literature that nests fiat money into the OG models introduced by Samuelson (1958). Lucas (1972) was the first to specify an environment explicitly to support a role for money as an object used to trade between generations. A subsequent work by Wallace (1980) showed that the OG structure provides a convenient setup in models where money serves as a medium of exchange, not only in models where money has a store of value. ${ }^{5}$

Our paper is closely related to the few papers that merge OG models with random matching monetary models. One of the first contributions to this literature is Maeda (1991) and, most recently, Zhu (2008). Maeda (1991) develops an OG model where fiat money is formalized similarly to Kiyotaki and Wright (1989), which is considered a first generation model of money (see Wright, 2005). Like Maeda, we have a goods market with frictions where money is essential. Unlike him, our model builds on Lagos and Wright (2005), a new generation monetary model that has more realistic assumptions and allows one to conduct policy analysis. Moreover, Maeda (1991) studies the existence of steady state equilibria, while we focus on different issues here. The closest paper to ours is perhaps Zhu (2008) who nests Lagos and Wright (2005) into an OG setup. Our OG setup is slightly different from Zhu (2008), however, both in terms of what agents can do when young and old, and in terms of the endowment to the initial old. Most important, unlike Zhu (2008), young and old agents receive different wages in our setup. This is crucial for the results. Finally, unlike Maeda (1991) and Zhu (2008), we run several numerical

\footnotetext{
${ }^{4}$ Since the output-unemployment relationship is an assumption, and not a result, our model is not able to provide an economic intuition of how inflation, and other variables, directly affect unemployment. Nevertheless, we are able to replicate the observed relationship between inflation and unemployment quite well.

${ }^{5}$ More recent works such as Freeman (1993) and Bhattacharyaa et al. (2005) study the optimality of the Friedman rule in OG models, as opposed to infinitely lived representative agent models. An up-to-date survey of this literature can be found in Shi (2006); Wright (2005) and Waller (2015).
} 
exercises and calibrate the model to the data.

Our paper also relates to the literature that studies the relationship between inflation and output in search and matching monetary models. A common result in this literature is that inflation negatively affects output since higher inflation induces agents to economize on their money holdings and thus to consume less in the goods market. However, some studies have shown that higher inflation may lead to higher output for low inflation rates if, for example, buyers can choose their search intensity (Lagos and Rocheteau, 2005) or if they are borrowing constrained (Berentsen et al., 2007a). We also find that higher inflation increases output for low inflation rates. This is because the centralized market consumption of young agents increases, while their goods market consumption stays efficient, for low inflation rates. As a result, money demand remains downward sloping, which allows us to replicate the relationship between money demand and nominal interest rates as observed in the data. In our model, this relationship comes directly from the OG structure.

Our paper is also related to the literature on money and unemployment such as Shi (1998) and Berentsen, Menzio, and Wright (2011). ${ }^{6}$ In Shi (1998), the decision-making unit is a household, which is formed by an infinite number of members, not the individual. Another difference with Shi (1998) is that we fit the model to the data while he does not. As in Berentsen, Menzio, and Wright (2011), our paper builds on Lagos and Wright (2005). Unlike Shi (1998) and Berentsen, Menzio, and Wright (2011), our environment has an OG structure and we do not model the labor market explicitly, but assume the validity of Okun's Law, to discuss unemployment. Although the theoretical framework is quite different, we think it is convenient to compare our empirical results with those in Berentsen, Menzio, and Wright (2011). We will do that in the numerical section.

Unlike all the above papers, we do not present a theory of unemployment, but assume a negative relationship between output and unemployment by advocating Okun's Law. ${ }^{7}$ We think this shortcut may have some advantages to the extent of which Okun's Law is stable. ${ }^{8}$ First,

\footnotetext{
${ }^{6}$ Recent papers in the unemployment literature have also studied financial frictions in over-the-counter markets (Rocheteau and Lopez, 2014), households' unsecured debt (Bethune et al., 2015), the housing market (Branch et al., 2016), and the effects of inflation on market participation and search intensity (Huangfu, 2018). For an extensive survey of the search and unemployment literature, we refer to Rogerson et al. (2005) and Lagos et al. (2017).

${ }^{7}$ Therefore, we are agnostic about the possible causes of unemployment. Another limitation of our model is that it may be subject to the Lucas's critique as Okun's Law is a pure empirical relationship. So our results may not be invariant to changes in policy variables.

${ }^{8}$ The stability of Okun's Law has been disputed over time (e.g., see Guisinger et al., 2018; Knotek, 2007). The main drawbacks of Okun's Law is that output is subject to measurement errors. Another drawback is that output can be affected by factors other than employment, such as productivity. There have been attempts to restore the stability of Okun's Law by introducing different measures of output. We rely on Meyer and Tasci
} 
there is more than one theory of unemployment and the choice of which theory to use is arbitrary. Second, our approach keeps the model relatively simple so we can focus on other issues, such as fitting the inflation and unemployment data. Third, although Okun's Law is a pure empirical relationship, the most common theories of unemployment are consistent with it. For example, in Rogerson (1988) higher employment leads to higher output since the production function is strictly increasing in labor. Similarly, in Mortensen and Pissarides (1994), an increase in employment translates into an increase in output, given that the worker's productivity remains the same. Hence, we conjecture that we would obtain similar results if we modelled the labor market as in Rogerson (1988), instead of relying on Okun's Law.

\section{The Environment}

Time is indexed by $t=0,1,2, \ldots$. At the beginning of each period there is a unit measure of newly born agents. Agents live for two periods and then die. In the first period of their life, agents are young, while in the second period of their life, they are old. At time $t=0$, there is a unit measure of the initial old who die at the end of the period. There are two perishable and perfectly divisible goods that can be produced and consumed in the economy. In each period, there are two competitive markets that open and close sequentially. In the first market, agents can produce and consume a general good. In the second market, agents are specialized in the production or consumption of the special good. We call these two markets the centralized market and the goods market, respectively.

The centralized market is a Walrasian market where agents enjoy utility $U(x)$ from consuming $x$ units of the general good. The utility function $U(x)$ is such that $U^{\prime}(x)>0,-U^{\prime \prime}(x)>0$, $U^{\prime}(0)=\infty$, and $U^{\prime}(\infty)=0$. There exists a linear production function that transforms $h$ units of labor into $h$ units of general goods. An agent receives a (real) wage $\omega(h)$ from working $h$ hours in the centralized market, and the wage differs between young and old agents. An old agent receives a wage per hour (or marginal wage) equal to $b<1$, while a young agent receives a wage per hour equal to

$$
\omega^{\prime}(h)= \begin{cases}1 & \text { if } h \leq \mathfrak{L}-\varepsilon \\ \in(b, 1) & \text { if } \mathfrak{L}-\varepsilon<h<\mathfrak{L}+\varepsilon \\ b & \text { if } h \geq \mathfrak{L}+\varepsilon\end{cases}
$$

(2012) for a survey about these attempts. In general, Okun's Law may be stable as far as the output and, in particular, the natural rate of unemployment are measured correctly (Wen and Chen, 2012). A recent work that documents the stability of Okun's Law is Ball et al. (2017). 
for some $\mathfrak{L}>0$ and $\varepsilon>0$ small enough. We let $\mathfrak{L}$ be a function of unemployment, $u$, which will be discussed later in detail. We also assume $\mathfrak{L}^{\prime}(u)<0$.

Before the goods market opens, young agents receive an idiosyncratic i.i.d. preference shock that determines their ability to produce or consume in the goods market. A young agent is a consumer in the goods market, with probability $n$, while he is a producer, with probability $1-n$. Old agents receive no preference shock and always consume in the goods market since they die at the end of the period. ${ }^{9}$ We refer to consumers as buyers and to producers as sellers.

A buyer enjoys utility $v(q)$ from $q$ consumption in the goods market. The function $v(q)$ satisfies the usual properties, namely $v^{\prime}(q)>0,-v^{\prime \prime}(q)>0, v^{\prime}(0)=\infty, v^{\prime}(\infty)=0$, and a coefficient of relative risk aversion $\alpha(q)=-q v^{\prime \prime}(q) / v^{\prime}(q) \leq 1$. For analytical tractability, we assume constant relative risk aversion; i.e., $\alpha(q)$ is independent of $q$. A seller suffers a disutility $q$ from producing $q$ units of the special good. Agents are anonymous and there is no recordkeeping technology in the goods market. Therefore, a medium of exchange is needed to facilitate trades in this market.

There is a perfectly storable, divisible, intrinsically useless object in the economy, called fiat money. A central bank exists that controls the money supply $M_{t}$ at time $t$. The initial stock of money, $M_{0}$, is equally distributed to the initial old. The gross growth rate of money supply at any time $t$ is denoted by $\gamma_{t}=M_{t+1} / M_{t}$. Money is injected (or withdrawn, if $\gamma_{t}<1$ ) through a lump-sum transfer $T_{t}$ to all agents, where $2 T_{t}=M_{t}-M_{t-1}=\left(\gamma_{t-1}-1\right) M_{t-1}$. Since all goods are perishable, there is no commodity money in the economy and fiat money is the only medium of exchange. Real money balances at time $t$ are defined as $\phi_{t} M_{t}$ where $\phi_{t}$ is the price of money in terms of the general good. Young agents discount between, but not within, periods at the rate $\beta \in(0,1)$.

\section{The Agent's Decision}

We now study the choice of a representative agent born at time $t$ by working backwards from the period where the agent is old to the period where he is young. To simplify notation, we omit the time subscript $t$ and shorten $t-1$ and $t+1$ with -1 and +1 , respectively.

\subsection{Old Agents}

Agents take the price of goods as given in the goods market. Since old agents die at the end of the goods market, they will consume and spend all their money in this market. Therefore, the

\footnotetext{
${ }^{9}$ We use this simplifying assumption because it solves the issue of bequests and does not affect our main results qualitatively.
} 
value function of an old agent entering the goods market with $m_{o,+1}$ units of money is

$$
\begin{aligned}
W_{o}\left(\phi_{+1} m_{o,+1}\right) & =v\left(q_{o,+1}\right), \\
\text { s.t. } \quad m_{o,+1} & =p_{+1} q_{o,+1},
\end{aligned}
$$

where $q_{o,+1}$ is consumption by an old agent, and $p_{+1}$ the unit price of the special good.

The value function of an old agent entering the centralized market with $\hat{m}_{o,+1}$ units of money is

$$
V_{o}\left(\phi_{+1} \hat{m}_{o,+1}\right)=\max _{x_{o,+1}, h_{o,+1}, m_{o,+1}} U\left(x_{o,+1}\right)-h_{o,+1}+W_{o}\left(\phi_{+1} m_{o,+1}\right),
$$

subject to

$$
x_{o,+1}+\phi_{+1} m_{o,+1}=b h_{o,+1}+\phi_{+1} \hat{m}_{o,+1}+\phi_{+1} T_{+1},
$$

where $x_{o,+1}$ is consumption of the general good, $h_{o,+1}$ hours of work, $b h_{o,+1}$ the real wage, $T_{+1}$ the lump-sum transfer, and $m_{o,+1}$ the amount of money carried into the goods market. It is well known that the choice of $m_{o,+1}$ is independent of $\hat{m}_{o,+1}$ due to the quasi linearity in consumption. Hence, old agents exit the centralized market with the same amount of money.

\subsection{Young Agents}

Let $W_{y}^{s}\left(\phi m_{y}\right)$ be the value function of a young agent who is a seller and enters the goods market with $m_{y}$ units of money. Then, his decision problem in the goods market is

$$
W_{y}^{s}\left(\phi m_{y}\right)=\max _{q^{s}}-q^{s}+\beta V_{o}\left(\phi_{+1} \hat{m}_{o,+1}\right)
$$

subject to

$$
\hat{m}_{o,+1}=m_{y}+p q^{s},
$$

where $q^{s}$ is the quantity of special goods he produces. The market clearing condition in the goods market implies that aggregate consumption of the special good is equal to aggregate production, i.e.

$$
n q_{y}+q_{o}=(1-n) q^{s}
$$

where $n q_{y}$ is aggregate consumption by young agents, $q_{o}$ aggregate consumption by old agents, and $(1-n) q^{s}$ aggregate production by young sellers. Notice that all the old agents consume, while only a fraction $1-n$ of young agents consume, in the goods market.

Now, let $W_{y}^{b}\left(\phi m_{y}\right)$ be the value function of a young agent who is a buyer and enters the goods market with $m_{y}$ units of money. Then, his problem in the goods market is 


$$
W_{y}^{b}\left(\phi m_{y}\right)=\max _{q_{y}} v\left(q_{y}\right)+\beta V_{o}\left(\phi_{+1} \hat{m}_{o,+1}\right)
$$

subject to

$$
p q_{y} \leq m_{y}, \quad \text { and } \quad \hat{m}_{o,+1}=m_{y}-p q_{y},
$$

where $W_{y}^{b}\left(\phi m_{y}\right)$ denotes his value function. The first constraint means that he cannot spend more money than he has. The second constraint means that the money he brings into the next period, $\hat{m}_{o,+1}$, equals the money he brought into the goods market less the money spent on consumption, $m_{y}-p q_{y}$.

Let $W_{y}\left(\phi m_{y}\right)$ denote the value function of a young agent with $m_{y}$ units of money, before the realization of the idiosyncratic preference shock. Then, the following holds,

$$
W_{y}\left(\phi m_{y}\right)=n W_{y}^{b}\left(\phi m_{y}\right)+(1-n) W_{y}^{s}\left(\phi m_{y}\right)
$$

Immediately after a young agent is born, he enters the centralized market with no endowments and faces the following problem:

$$
V_{y}=\max _{x_{y}, h_{y}, m_{y}} U\left(x_{y}\right)-h_{y}+W_{y}\left(\phi m_{y}\right)
$$

subject to

$$
x_{y}+\phi m_{y}=\omega\left(h_{y}\right)+\phi T,
$$

where $x_{y}$ is the quantity of general goods he consumes, $h_{y}$ is hours of work, $\omega\left(h_{y}\right)$ is the real wage he earns from working $h_{y}$ hours, $T$ is the lump-sum money transfer, and $m_{y}$ the amount of money carried into the goods market.

\section{$5 \quad$ Equilibria}

We focus on symmetric steady state equilibria, where all agents follow identical strategies and real variables are constant over time. Since the Fisher equation holds in our model, then the following holds too

$$
\beta(1+i)=\gamma=\phi / \phi_{+1}
$$

where we have used $\phi M=\phi_{+} M_{+}$, and the term $i$ denotes the nominal interest rate.

In any monetary equilibrium, we obtain the following two conditions from an old agent's 
decision problem:

$$
\begin{aligned}
v^{\prime}\left(q_{o}\right) & =1+i, \\
U^{\prime}\left(x_{o}\right) & =b^{-1} .
\end{aligned}
$$

These conditions are standard and their derivation is in Appendix B. Equation (2) means that the benefit from having an additional unit of money in the goods market, $v^{\prime}\left(q_{o}\right)$, must be equal to the marginal cost of holding money, $\gamma / \beta$. Similarly, (3) means that the marginal benefit of acquiring an additional unit of the general good, $U^{\prime}\left(x_{o}\right)$, must be equal to its marginal cost, $1 / b$.

For a young agent, there are two types of equilibria depending on the opportunity cost of holding money, $i$. When $i$ is low enough, a young agent consumes the efficient quantity $q^{*}$ in the goods market, where $q^{*}$ solves $v^{\prime}\left(q^{*}\right)=1$, and works $h_{y}$ hours, with $\mathfrak{L}-\varepsilon<h_{y}<\mathfrak{L}+\varepsilon$, in the centralized market. When $i$ is high enough, a young agent consumes the inefficient quantity $q$ in the goods market, where $q<q^{*}$, and works $h_{y}$ of hours, with $h_{y}<\mathfrak{L}-\varepsilon$. We show below that these two equilibria emerge in the calibration and we refer to them as type-I and type-II, respectively. ${ }^{10}$

In a type-I equilibrium, the cash constraint of a young buyer is non-binding in the goods market, and young agents work more than $\mathfrak{L}-\varepsilon$ and less than $\mathfrak{L}+\varepsilon$. A type-I equilibrium is defined by the following:

Proposition 1 A type-I equilibrium is a list $\left\{q_{o}, q_{y}, x_{o}, x_{y}\right\}$ satisfying (2), (3),

$$
\begin{aligned}
v^{\prime}\left(q_{y}\right) & =1, \\
U^{\prime}\left(x_{y}\right) & =[b(1+i)]^{-1} .
\end{aligned}
$$

Equation (4) states that young buyers consume the efficient quantity $q^{*}$ in the goods market, which solves $v^{\prime}\left(q^{*}\right)=1$. Equation (5) shows that centralized market consumption of young agents is increasing in the nominal interest rate $i$. Under the Friedman rule, $i=0$, the marginal wage of young agents is equal to that of old agents; i.e., $\omega^{\prime}\left(h_{y}\right)=b(1+i)=b .{ }^{11}$ This means that young agents work a lot in order to save for goods market consumption and their retirement.

\footnotetext{
${ }^{10}$ Other equilibria are feasible. We find an equilibrium where a young buyer consumes the inefficient quantity in the goods market, and works $h_{y}$ hours, with $h_{y}>\mathfrak{L}+\varepsilon$. There exists also an equilibrium where a young agent consumes the inefficient quantity, and works $h_{y}$ hours, with $\mathfrak{L}-\varepsilon<h_{y}<\mathfrak{L}+\varepsilon$. These equilibria are not discussed here and we refer to Huber and Kim (2018) for more details.

${ }^{11}$ Strictly speaking, the type-I equilibrium does not exist at the Friedman rule, since it is defined as $\omega^{\prime}\left(h_{y}\right)$ $\in(b, 1)$.
} 
This is so because they want to benefit from their higher wage when being young. As the opportunity cost of holding money increases, saving becomes less attractive and thus young agents decide to work and save less in order to consume more today.

Note that in a type-I equilibrium, young agents consume the efficient quantity $q^{*}$, but old agents consume less than $q^{*}$. This is so because when an agent becomes old it is very costly for him to save money for the goods market due to the low wage. Thus, he prefers more leisure in the centralized market (marginal benefit of $1 / b>1$ ) in comparison with more consumption in the goods market, which generates the marginal benefit $v^{\prime}(q) /(\phi p)<v^{\prime}\left(q_{o}\right) /(\phi p)=1 / b$, where $\phi p=b(1+i)$ is the relative price of the special good with respect to leisure.

In a type-II equilibrium, the cash constraint of a young buyer is binding in the goods market, and young agents work $h_{y}<\mathfrak{L}-\varepsilon$. A type-II equilibrium is characterized by the following:

Proposition 2 A type-II equilibrium is a list $\left\{q_{o}, q_{y}, x_{o}, x_{y}\right\}$ satisfying (2), (3), and

$$
\begin{aligned}
v^{\prime}\left(q_{y}\right) & =\frac{b(1+i)-(1-n)}{n}, \\
U^{\prime}\left(x_{y}\right) & =1 .
\end{aligned}
$$

Equation (6) states that the consumption of young agents is inefficiently low in the goods market for any $i>1 / b-1$. Equation (7) shows that the centralized market consumption of young agents is efficient and independent of monetary policy. In a type-II equilibrium, young agents choose to consume more goods in the centralized market by reducing their savings for the goods market. In addition, $\omega^{\prime}\left(h_{y}\right)=1$ implies that young agents optimally choose to maximize the marginal wage.

We find the following sequence of equilibria as the nominal interest rate $i$ increases from 0 to infinity: type-I, and type-II. This finding is summarized by the following

Proposition 3 If $i<1 / b-1$, equilibrium prices and quantities are characterized by Proposition 1; if $i>1 / b-1$, they are characterized by Proposition 2.

For low interest rates (i.e. $i<1 / b-1$ ), the type-I equilibrium exists. Since the opportunity cost of holding money is lower in a type-I equilibrium, as opposed to a type-II equilibrium, young agents save more and consume less in the centralized market. Due to the higher savings, they can afford to consume the optimal amount of goods, $q_{y}=q^{*}$, in the goods market in case they become buyers. Since the opportunity cost of holding money is low, young agents want to benefit from their higher wage and thus work more in the type-I equilibrium than in the type-II 
equilibrium; i.e., we have $\mathfrak{L}-\varepsilon<h_{y}<\mathfrak{L}+\varepsilon$. Since $\omega^{\prime}\left(h_{y}\right)>\omega^{\prime}\left(h_{o}\right)=b$, young agents still consume more centralized market goods than old agents.

For higher nominal interest rates (i.e. $i>1 / b-1$ ), the type-II equilibrium exists. In this equilibrium, the opportunity cost of holding money is high, so young agents prefer to consume more and save less in the centralized market, than in the type-I equilibrium. Conversely, fewer savings in the centralized market will make them consume less in the goods market. Therefore, their consumption is inefficient in the goods market, $q_{y}<q^{*}$. Finally, a higher opportunity cost of holding money results in less work in the centralized market, $h_{y}<\mathfrak{L}-\varepsilon$.

\section{Unemployment}

We do not model unemployment explicitly. Instead, we assume that it is negatively related to aggregate output. This assumption is consistent both with the empirical evidence (Okun's Law), as discussed before, and with the theory (for example, Mortensen and Pissarides, 1994; Rogerson, 1988).

In order to find out how unemployment evolves as a function of monetary policy, we first analyze how aggregate output behaves. In our model, total output is given by

$$
\begin{aligned}
Y & =x_{y}+x_{o}+p \phi\left(n q_{y}+q_{o}\right) \\
& =x_{y}+x_{o}+b(1+i)\left(n q_{y}+q_{o}\right),
\end{aligned}
$$

and $b(1+i)$ equals the relative price of the special good in terms of the general good. Differentiating the above equation with respect to $i$ yields

$$
\frac{\partial Y}{\partial i}=\frac{\partial x_{y}}{\partial i}+\frac{\partial x_{o}}{\partial i}+b\left(n q_{y}+q_{o}\right)+b(1+i)\left(n \frac{\partial q_{y}}{\partial i}+\frac{\partial q_{o}}{\partial i}\right) .
$$

In the type-I and type-II equilibria, we always have $\partial x_{o} / \partial i=0$. Additionally, in the type-I equilibrium we have $\partial q_{y} / \partial i=0$ while in the type-II equilibrium we have $\partial x_{y} / \partial i=0$. Hence, we can rewrite (8) as

$$
\frac{\partial Y}{\partial i}= \begin{cases}-\frac{1}{b(1+i)^{2} U^{\prime \prime}\left(x_{y}\right)}+b\left(n q_{y}+q_{o}\right)+b \frac{v^{\prime}\left(q_{o}\right)}{v^{\prime \prime}\left(q_{o}\right)} & \text { if } i<1 / b-1 \\ b\left(n q_{y}+q_{o}\right)+b\left(\frac{n v^{\prime}\left(q_{y}\right)+(1-n)}{v^{\prime \prime}\left(q_{y}\right)}+\frac{v^{\prime}\left(q_{o}\right)}{v^{\prime \prime}\left(q_{o}\right)}\right) & \text { if } i \geq 1 / b-1\end{cases}
$$

Proposition 4 below formalizes a condition under which aggregate output $Y$ is increasing in 
the nominal interest rate $i$ in the type-I equilibrium.

Proposition $4 \partial Y / \partial i>0$ in the type-I equilibrium if and only if $\alpha>\bar{\alpha}(i)$ for some $\bar{\alpha}(i)<$ $(1+n)^{-1}$.

In the proof of Proposition 4, we show that (9) can be simplified as follows in the type-I equilibrium:

$$
\frac{\partial Y}{\partial i}=-\frac{1}{b(1+i)^{2} U^{\prime \prime}\left(x_{y}\right)}+b n q_{y}+b q_{o} \frac{\alpha-1}{\alpha} .
$$

The first two terms are always positive. The intuition behind this result is that young agents' consumption in the goods market is not affected by monetary policy, since $q_{y}=q^{*}$, while centralized market consumption is increasing in the interest rate. Hence, only the goods market consumption of old agents (the third term on the right hand side) contributes negatively to $\partial Y / \partial i$. This term is decreasing in $\alpha$. In other words, the higher the risk aversion of old agents, the lower the negative impact that inflation has on goods market consumption by old agents, and vice versa. For high $\alpha$, the positive contribution by young agents in the goods market (second term) dominates that by old agents (third term), and aggregate output is increasing in the nominal interest rate. For low values of $\alpha$, the opposite holds and the third term dominates such that $\partial Y / \partial i<0$.

Following Proposition 4, we can summarize the implications of the negative relationship between unemployment and output in the type-I equilibrium. If the relative risk aversion is sufficiently high, aggregate output is increasing in the nominal interest rate while unemployment is decreasing in it. As a result, $\mathfrak{L}$ is increasing in $i$ and both the marginal wage, $\omega^{\prime}\left(h_{y}\right)$, and the average wage, $\omega\left(h_{y}\right) / h_{y}$, are increasing in $i$. In this sense, wages are procyclical.

Proposition 5 states that aggregate output is decreasing in the nominal interest rate in a type-II equilibrium for any $\alpha \leq 1$.

Proposition $5 \partial Y / \partial i<0$ in the type-II equilibrium.

In the proof of Proposition 5, we show that (9) can be simplified as follows in a type-II equilibrium:

$$
\frac{1}{b} \frac{\partial Y}{\partial i}=\frac{1-n}{v^{\prime \prime}\left(q_{y}\right)}+\frac{\alpha-1}{\alpha}\left(n q_{y}+q_{o}\right)
$$

Since the sign of the first term is always negative, it is obvious that $\partial Y / \partial i<0$ for any $\alpha \leq 1$.

According to Proposition 5, aggregate output is decreasing in the nominal interest rate and unemployment is increasing in it. Therefore, $\mathfrak{L}$ is decreasing in the interest rate while both the marginal wage and the average wage stay constant. Therefore, wages are sticky downwards. 


\section{Quantitative Analysis}

We have shown that the unemployment rate can be negatively related to the nominal interest rate for low interest rates $(i<1 / b-1)$, while the opposite is the case for high nominal interest rates $(i<1 / b-1)$. We now calibrate our model to U.S. data in order to verify whether our results are consistent with empirical evidence. We then compare the fitness of our model to that of Berentsen, Menzio, and Wright (2011).

We choose one year as a model period. For preferences and technology, we use the following functional forms: $v(q)=A_{1} q^{1-\alpha_{1}} /\left(1-\alpha_{1}\right)$ and $U(x)=A_{2} q^{1-\alpha_{2}} /\left(1-\alpha_{2}\right)$, where $\alpha_{j}$ for $j=1,2$ represents the constant relative risk aversion in the respective markets. Furthermore, we use the following functional form to relate output and unemployment:

$$
\frac{Y-Y^{*}}{Y^{*}}=-c\left(u-u^{*}\right)
$$

where $Y^{*}$ is potential output, $u$ the unemployment rate, $u^{*}$ the natural rate of unemployment, and $c>0$ a scaling parameter. We define $Y^{*}$ as the maximum level of output achievable in the model; i.e., the output level associated to $i=1 / b-1$.

The parameters to be identified are (i) preference parameters: $\beta, A_{1}, \alpha_{1}, A_{2}, \alpha_{2}$; (ii) technology parameters: $u^{*}, c, n, b$; (iii) and the policy parameter $i$. We identify these parameters by using U.S. data from the first quarter of 1959 to the second quarter of $2018 .{ }^{12}$ We set $i$ equal to its target value (0.046), where we interpret $i$ as the annual nominal interest rate on a 3 -month T-Bill. The rate of time preference, $\beta=1 /(1+r)$, is set equal to 0.99 , where the real interest rate, $r$, is obtained by subtracting the average inflation rate from the nominal interest rate. Furthermore, we normalize $n=0.5$ and set $u^{*}=0.04 .{ }^{13}$ The remaining unknown parameters, $A_{1}, \alpha_{1}, A_{2}, \alpha_{2}, c$, and $b$, are identified simultaneously by minimizing the sum of mean-adjusted squared differences between the model-implied and the observed money demand, and also between the model-implied and the observed unemployment rate. Money demand is defined according to the Quantity Theory of Money, $\mathcal{M D}=\phi M / Y$, where $\phi M$ denotes the real stock of money. ${ }^{14}$ In our model, the real stock of money is given by the real money holdings of young and old agents, $\phi m_{y}$ and $\phi m_{o}$, respectively. After simple algebra, the real stock of money

\footnotetext{
${ }^{12}$ Details of the data sources are provided in Appendix C.

${ }^{13} \mathrm{~A}$ value of $u^{*}=0.04$ is in the range of the September 2018 projections of FOMC participants' estimates of the longer-run normal rate of unemployment, which is in the range from 4.0 to 4.6 percent.

${ }^{14}$ We measure money demand in the data as the ratio of Money Zero Maturity (MZM) divided by the nominal gross domestic product. MZM is calculated by the St. Louis Fed and represents M2 less small-denomination time deposits plus institutional money funds.
} 
in the two equilibria is the following:

$$
\phi M= \begin{cases}\frac{2 \beta(1+i)\left[\omega\left(h_{y}\right)-x_{y}+b(1+i) q_{o}\right]}{1+\beta(1+i)} & \text { if } i<1 / b-1, \\ b(1+i)\left(q_{y}+q_{o}\right) & \text { if } i \geq 1 / b-1 .\end{cases}
$$

To derive the first line in the right hand side of the above expression, note that old buyers spend all their money in the goods market in the type-I equilibrium. Therefore, $\phi m_{o}=\phi p q_{o}=$ $b(1+i) q_{o}$. In the type-I equilibrium, real money holdings of young agents are determined by the budget constraint in the centralized market, $\phi m_{y}=\omega\left(h_{y}\right)+\phi T-x_{y}$. Also, note that $M_{+1}=M+2 T_{+1}$, where $T_{+1}$ is the individual lump-sum transfer to each agent (young and old). Substituting and rearranging terms, we have $T=[1-1 / \beta(1+i)] M / 2$. Hence,

$$
\begin{aligned}
\phi M & =\phi m_{y}+\phi m_{o} \\
& =\omega\left(h_{y}\right)+\phi T-x_{y}+b(1+i) q_{o} \\
& =\omega\left(h_{y}\right)+\left[1-\frac{1}{\beta(1+i)}\right] \frac{\phi M}{2}-x_{y}+b(1+i) q_{o} .
\end{aligned}
$$

Solve the last equation with respect to $\phi M$ to obtain the real stock of money in the type-I equilibrium. In the type-II equilibrium, both old and young buyers spend all their money in the goods market, therefore $\phi m_{o}=\phi p q_{o}=b(1+i) q_{o}$ and $\phi m_{y}=\phi p q_{y}=b(1+i) q_{y}$. The sum of the last two terms gives us the real stock of money holdings in a type-II equilibrium.

The money demand in the model is given by the following expression:

$$
\mathcal{M D}= \begin{cases}\frac{2 \beta(1+i)\left[\omega\left(h_{y}\right)-x_{y}+b(1+i) q_{o}\right]}{[1+\beta(1+i)]\left[x_{y}+x_{o}+b(1+i)\left(n q_{y}+q_{o}\right)\right]} & \text { if } i<1 / b-1 \\ \frac{b(1+i)\left(q_{y}+q_{o}\right)}{x_{y}+x_{o}+b(1+i)\left(n q_{y}+q_{o}\right)} . & \text { if } i \geq 1 / b-1\end{cases}
$$

With the above expression, we are now able to calibrate the unknown parameters, which are shown in Table 1. Using these parameter values, we obtain a sum of mean-adjusted squared differences equal to 17.9 .

For a comparison with previous studies, we recalibrate BMW's model by using the calibrated parameter values as stated in their paper, except for $(b+l) / w, A$ and $\alpha$. These parameters are recalibrated by following the same procedure as for our model; i.e., by minimizing the sum of squared mean-adjusted differences between the model-implied and the observed money demand and between the model-implied and the observed unemployment rate. From BMW's model 
TABle 1: CAlibration RESUlts FOR The U.S. ${ }^{\dagger}$

\begin{tabular}{lcccccccccc}
\hline \hline Method & $A_{1}$ & $\alpha_{1}$ & $A_{2}$ & $\alpha_{2}$ & $b$ & $c$ & $A$ & $\alpha$ & $(b+l) / w$ & $\Sigma$ sq. diff. \\
\hline Our model & 0.70 & 0.18 & 0.90 & 0.07 & 0.97 & 3.52 & - & - & - & 17.9 \\
BMW & - & - & - & - & - & - & 0.95 & 0.50 & 0.94 & 31.6 \\
\hline
\end{tabular}

${ }^{\dagger}$ Table 1 displays the calibrated values for the key parameters of our model $A_{1}, \alpha_{1}, A_{2}, \alpha_{2}, b$, and $c$. Table 1 also displays the recalibrated parameter values for BMW: $A, \alpha$, and $i(b+l) / w$. Finally, the table shows the sum of squared meanadjusted differences ( $\Sigma$ sq. diff) between the model-implied money demand and the data and between the model-implied unemployment rate and the data.

we obtain a sum of mean-adjusted squared differences equal to 31.6, as compared to 17.9 for our model. Although the assumption about the output-unemployment relationship is different in the two papers, the improved fit seems to be driven mainly by the different environment, OG vs infinitely lived agents. Note that BMW model the labor market as in Mortensen and Pissarides (1994) which implies that unemployment and output are negatively related, given that the agent's productivity is the same.

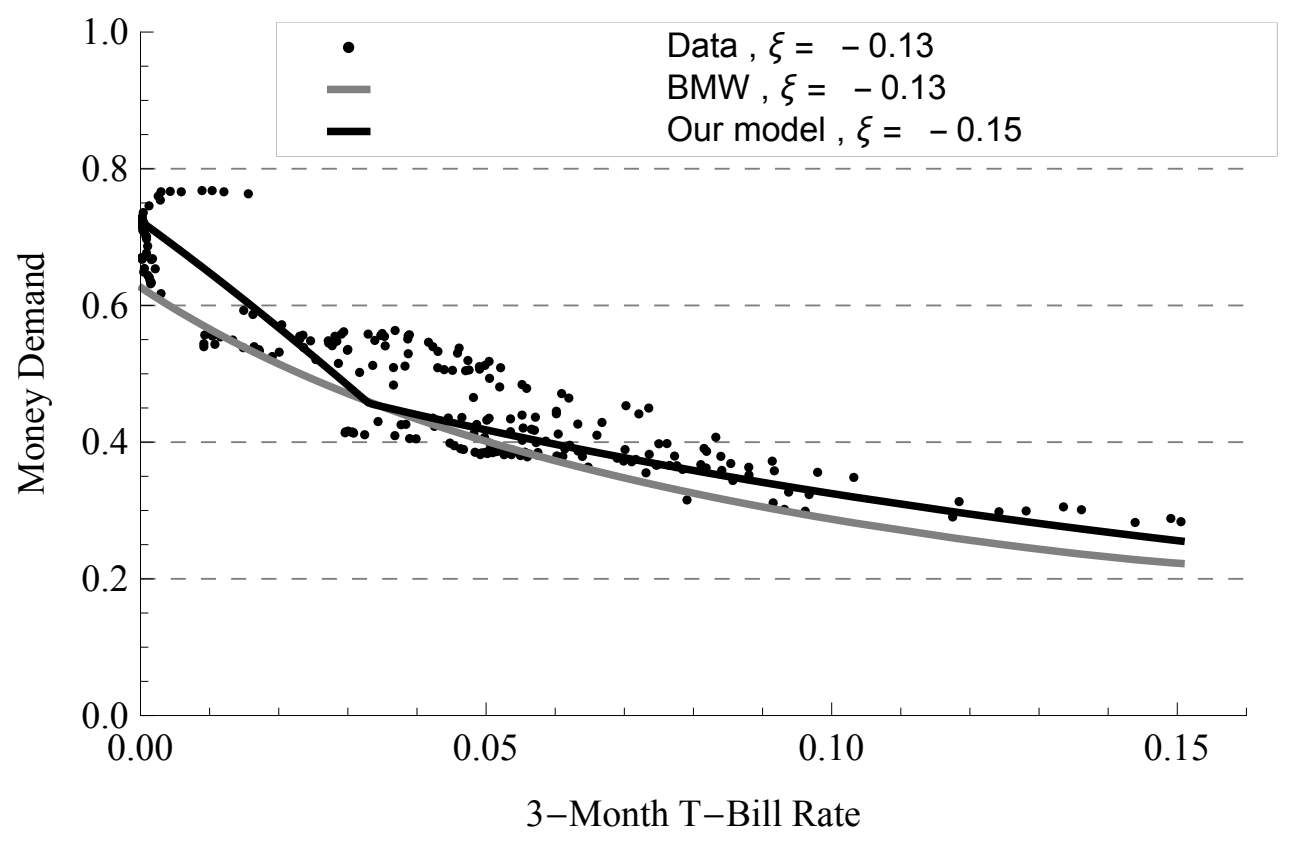

Figure 3: Money Demand 
Simulation Holding all calibrated parameters constant, we input the actual time series of nominal interest rates, and simulate the model-implied unemployment and money demand, for both, our model and BMW. Figure 3 compares the simulated money demand function to that observed in the U.S. data, where the term $\xi$ denotes the elasticity of money demand with respect to nominal interest rates. ${ }^{15}$ The figure shows that, for low nominal interest rates, our model improves the fit by generating a larger money demand than that in BMW. This is because, for low nominal interest rates, the economy ends up in the type-I equilibrium, where agents increase their savings and therefore demand more money. This finding is in contrast to previous studies building on Lagos and Wright (2005) who find an output-enhancing role of inflation. For instance, Rocheteau and Wright (2005, 2009), and Berentsen et al. (2007a,b, 2018) imply that money demand is upward sloping in a such a case. This is because goods market consumption is increasing in $i$ in these studies, while in our model centralized market consumption is increasing in $i$. From the definition of money demand, it is evident that centralized market consumption has an opposite effect on money demand when compared with goods market consumption.

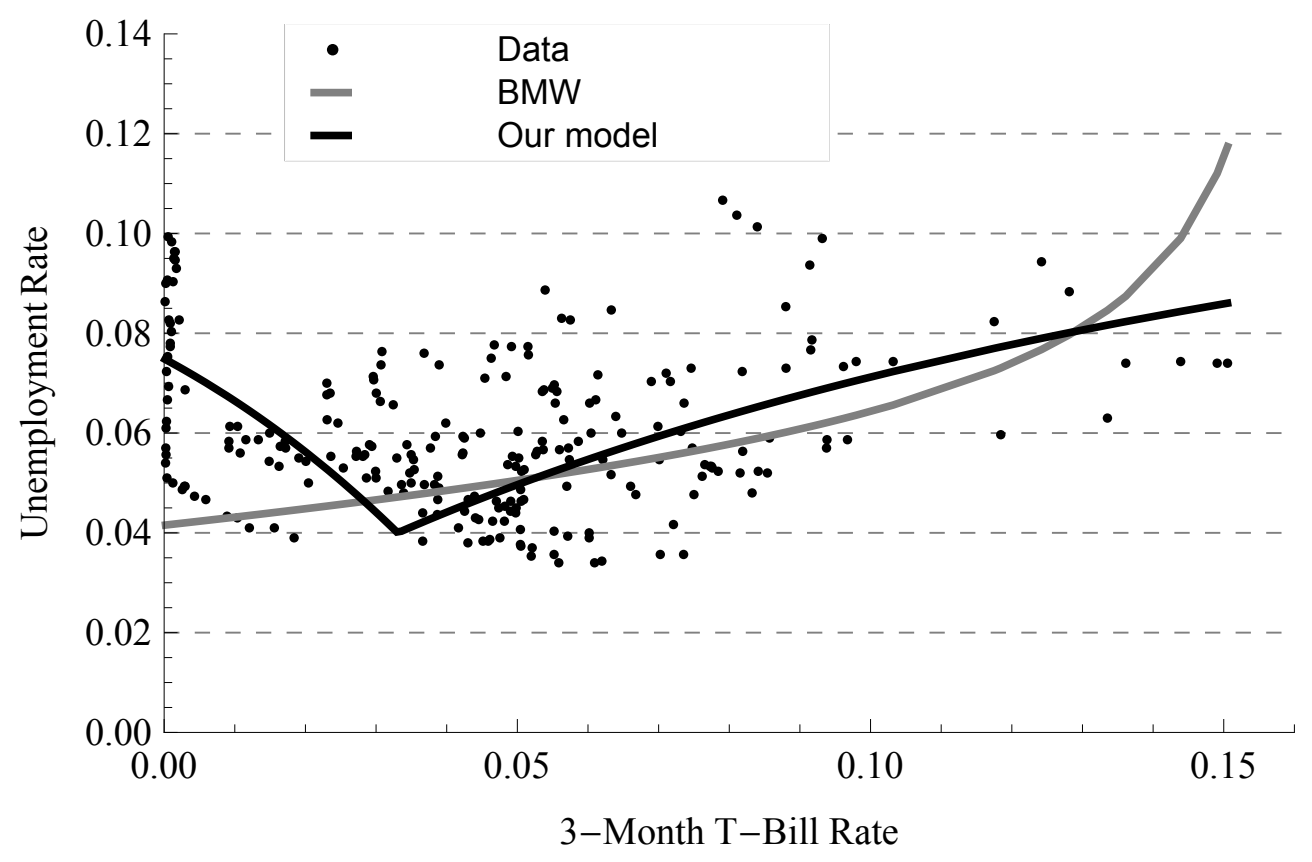

Figure 4: Monetary POLICY Vs. UnEMPlOyMENT

In Figure 4 we perform the same exercise and show the empirical and the model-implied

\footnotetext{
${ }^{15}$ The elasticity of money demand is estimated by using ordinary least squares and a log-log specification.
} 
relationship between nominal interest rates and unemployment. While BWM's model implies an increasing relationship, our model predicts for $i<1 / b-1$ a decreasing relationship and for $i>$ $1 / b-1$ an increasing one. This feature is helpful to replicate the movement in the unemployment rate in the early 1960s and the post-1990s period, as Figure 1 shows. Our improved fit in these subsample periods is because we are able to track the swings in unemployment, which is where we observe a downward sloping Phillips curve. This evidence suggests that the discovered channel by which monetary policy affects labor markets matters.

\section{$7.1 \quad$ Robustness}

As a robustness check, we are going to present the calibration results for Canada and the United Kingdom as well. For these two countries, we found a comparable data set for nearly the same sample period as for the US. As before, we keep $n=0.5$, set $u^{*}=0.04$ and set $i$ equal to the annual nominal interest rate on a 3 -month Treasury security. Finally, we calibrate the unknown parameters $A_{1}, \alpha_{1}, A_{2}, \alpha_{2}, c$, and $b$, by minimizing the sum of mean-adjusted squared differences between the model-implied and the observed money demand and between the model-implied and the observed unemployment rate. As before, we recalibrate the unknown parameters of BMW -i.e., $(b+l) / w, A$, and $\alpha$ - by following the same procedure.

Canada For Canada, we use quarterly data from the first quarter of 1961 to the first quarter of 2018. As for the United States, our modelling approach allows us to significantly improve the combined fit of money demand and unemployment when compared with BMW; i.e., we obtain a sum of squared mean-adjusted differences which is roughly 50 percent lower. Also for Canada, our theory allows us to improve the model-implied evolution of unemployment in the 1960s and 1970s as well as in the post-2000 period. Both of these periods were characterized by relatively low nominal interest rates and Figure 5B shows that our model closely tracks the data in such environments. To the contrary, the 1975 to 2000 period was characterized by an above-the-average nominal interest rates and is similarly tracked by both models. In terms of money demand, our model allows us to replicate the high elasticity of money demand for low nominal interest rates and the intermediate elasticity for higher nominal interest rates. The calibration results for Canada are shown in Table 2.

U.K. For the U.K., we use quarterly data from the first quarter of 1960 to the third quarter of 2016. Since we could not find a quarterly inflation time series back to 1960, we follow Berentsen et al. (2018) and choose $\beta=(1+r)^{-1}=0.968$. Also for the U.K., our modelling approach allows us to improve the combined fit of money demand and unemployment when compared 
Table 2: Calibration Results For CAnadA ${ }^{\dagger}$

\begin{tabular}{lcccccccccc}
\hline \hline Method & $A_{1}$ & $\alpha_{1}$ & $A_{2}$ & $\alpha_{2}$ & $b$ & $c$ & $A$ & $\alpha$ & $(b+l) / w$ & $\Sigma$ sq. diff. \\
\hline Our model & 0.71 & 0.23 & 0.90 & 0.06 & 0.95 & 2.90 & - & - & - & 32.7 \\
BMW & - & - & - & - & - & - & 1.35 & 0.35 & 1.07 & 67.5 \\
\hline
\end{tabular}

$\nmid$ Table 2 is Table 1's counterpart for Canada. For a description of the reported variables, we refer the reader to Table 1.

(A) Money Demand

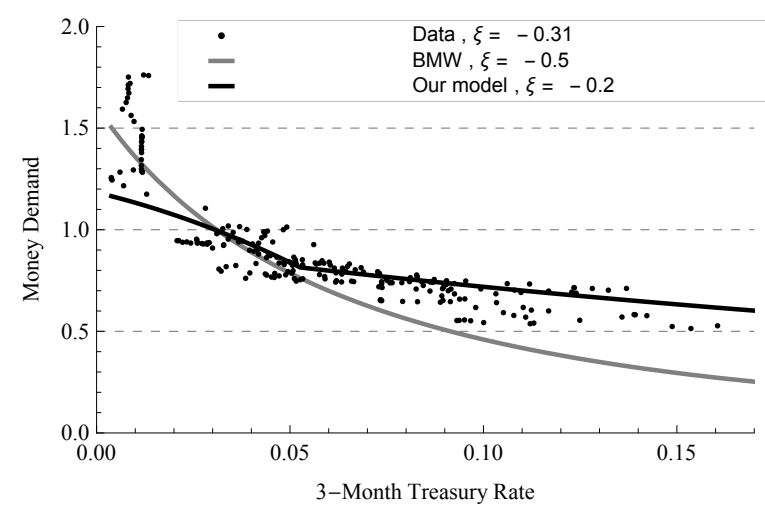

(B) UnEMPLOYMENT

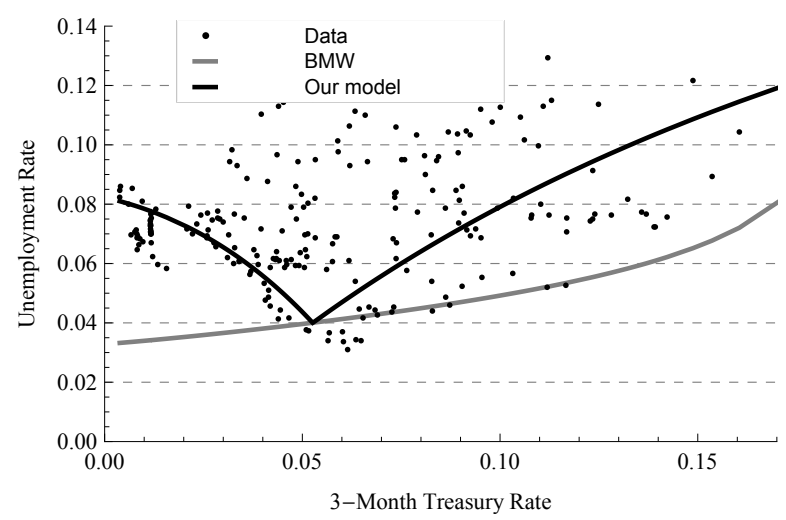

Figure 5: Calibration Results for CAnada

with BMW, although to a lesser extent. That is, we obtain a sum of squared mean-adjusted differences which is roughly 30 percent lower. The main reason for this setback is that our model does not track money demand closely and understates the elasticity of money demand, as shown by Figure 6A. In terms of unemployment, we observe again that our model improves the fit in the 1960s and 1970s as well as in the post-2000 period, as shown by Figure 6B. The calibration results for the U.K. are summarized in Table 3.

TABle 3: CAlibration Results For the U.K. ${ }^{\dagger}$

\begin{tabular}{lcccccccccc}
\hline \hline Method & $A_{1}$ & $\alpha_{1}$ & $A_{2}$ & $\alpha_{2}$ & $b$ & $c$ & $A$ & $\alpha$ & $(b+l) / w$ & $\Sigma$ sq. diff. \\
\hline Our model & 0.73 & 0.29 & 0.90 & 0.06 & 0.96 & 3.45 & - & - & - & 51.9 \\
BMW & - & - & - & - & - & - & 1.35 & 0.35 & 0.90 & 71.0 \\
\hline
\end{tabular}

$\dagger$ Table 3 is Table 1's counterpart for the United Kingdom. For a description of the reported variables, we refer the reader to Table 1. 
(A) Money Demand

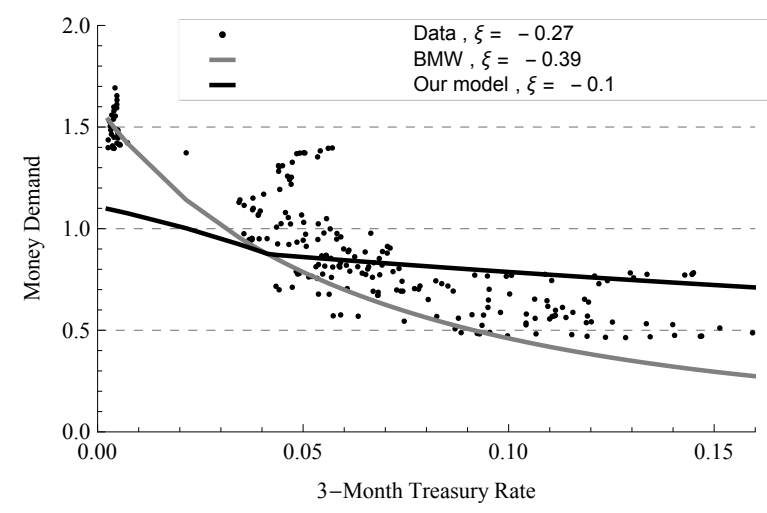

(B) UNEMPLOYMENT

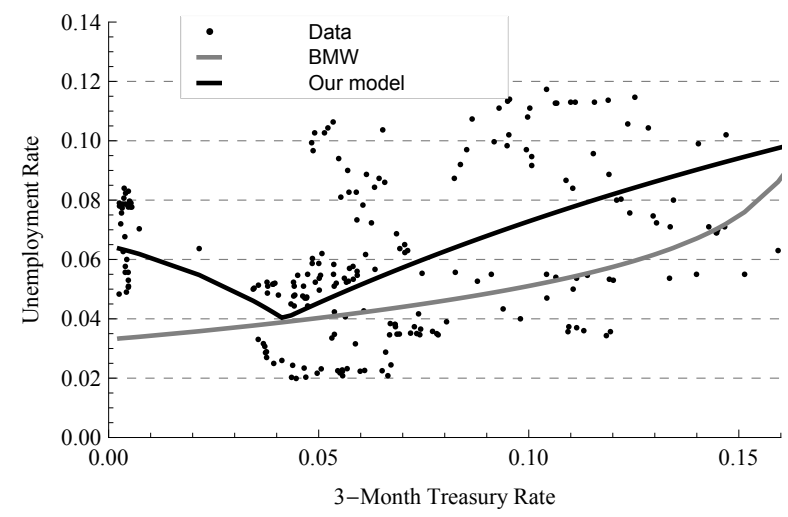

Figure 6: Calibration Results For the U.K.

\subsubsection{Discussion of Robustness Results}

The integration of an OG structure into Lagos and Wright (2005) allows us to replicate a downward sloping Phillips curve for low nominal interest rates and an upward sloping curve for higher interest rates quite well, whereas previous models fails to do so. Furthermore, as predicted by our model, we find a higher elasticity of money demand for low nominal interest rates in comparison with high nominal interest rates, which is in line with the empirical findings presented above. Since our model succeeds in replicating these counterparts in the data, it generates a lower sum of squared mean-adjusted differences when compared with BMW. We therefore believe that our theory helps us to better understand the impact of monetary policy in low inflation environments. As supported by the empirical findings for the U.S., Canada and the U.K., such environments tend to be described by a downward sloping Phillips curve.

\section{Discussion}

Comparison with BMW Hereafter, we discuss the main differences between our study and Berentsen, Menzio, and Wright (2011). In BMW's model, in each period there are three markets that open sequentially: a labor market, a goods market, and a centralized market. One of the main differences is obviously the setting of the labor market. In BMW's model, each worker exogenously provides one unit of labor in each period. But in our model, each agent chooses an optimal amount of labor as in the standard Lagos and Wright (2005) framework. In turn, the wage is endogenously determined in BMW's model, which is not the case in our model. 
There are three reasons why we chose an endogenous amount of labor and an exogenous wage instead of an exogenous amount of labor and an endogenous wage. First, an exogenous labor amount might be a strong assumption under an OG model. Second, it might not be a good idea to divide agents into a few groups (e.g. employed and unemployed as in BMW's model) under an OG structure. If we did so, there would only be two types of agents, employed and unemployed, for their entire youth. Third, if we switch the endogeneity and exogeneity of our labor market setting, we would lose the tractability in our model.

TABle 4: Comparison With BMW and LW

\begin{tabular}{llll}
\hline \hline Description & Our model & BMW & LW \\
\hline wage & exogenous & endogenous & exogenous \\
hours worked & endogenous & exogenous & endogenous \\
OG & yes & no & no \\
saving for retirement & yes & no & no \\
\hline
\end{tabular}

In Table 4, we summarize the main differences between our model and Lagos and Wright (2005). Due to the OG framework, in our model agents save money for their retirement as compared to the other two frameworks. As a result, we obtain a hump-shaped relationship between inflation and output, which translates into a U-shaped relationship between inflation and unemployment due to the Okun's Law.

Application of Okun's Law Okun's Law describes the empirical relationship between output and unemployment. In our model, we have assumed that this relationship always holds. By doing so, we could link output and unemployment and were able to show that our model succeeds in explaining the u-shaped relationship between nominal interest rates and unemployment as observed in the data. The reason behind this result is that our model implies a hump-shaped relationship between nominal interest rates and output if agents' risk aversion is sufficiently high.

Thus, in periods where Okun's Law holds, we would expect to observe a hump-shaped pattern between nominal interest rates and real output as implied by our model. We therefore checked the data for all the three countries analyzed and can confirm that this relationship holds empirically. For ease of reference, we show in Figure 7 the relationship between nominal interest rates and output for the United States. As before, we use the annual nominal interest rate on a 3-month T-Bill to represent $i$. To represent output, we use the annual growth rate of the real gross domestic product. Figure 7 shows the raw data as well as the trend time series in black. ${ }^{16}$

\footnotetext{
${ }^{16}$ For the calculation of the trend time series, we apply a Hodrick-Prescott filter with a value of $\lambda=1600$.
} 


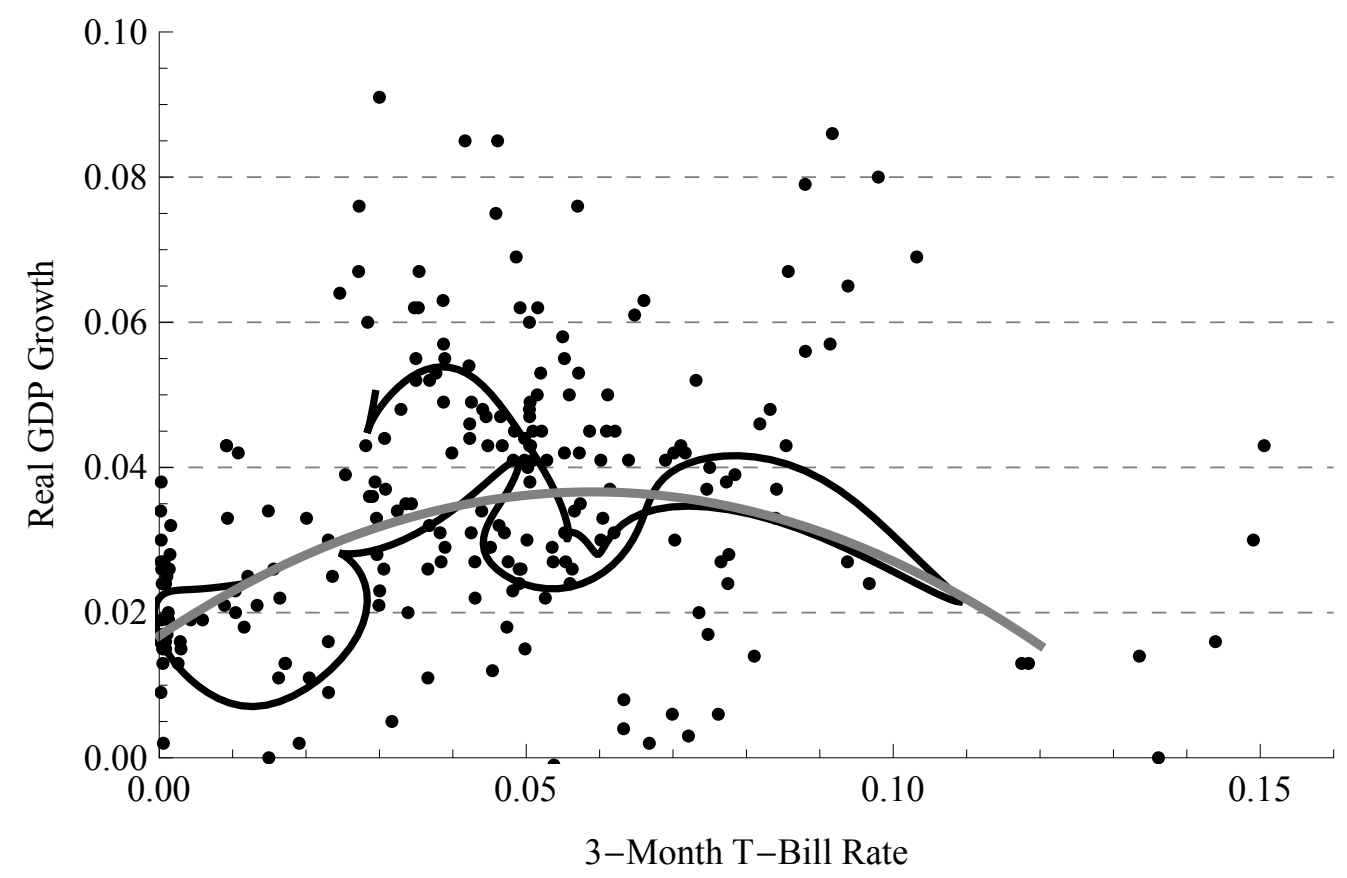

Figure 7: Relationship BETWEen OUTPUT AND NOMINAL INTEREST RATES FOR THE U.S.

In gray, we represent the second-order polynomial trend, which clearly shows the hump-shaped relationship as implied by our model.

Sticky Wages In Section 6, we showed that in the type-I equilibrium wages are procyclical, since $\mathfrak{L}$ is increasing in $i$ and the marginal wage $\omega^{\prime}\left(h_{y}\right)$ as well as the average wage $\omega\left(h_{y}\right) / h_{y}$ increase. Furthermore, we found that in the type-II equilibrium wages are sticky downwards, since $\mathfrak{L}$ is decreasing in $i$ and the marginal wage $\omega^{\prime}\left(h_{y}\right)$ as well as the average wage $\omega\left(h_{y}\right) / h_{y}$ stay constant.

We therefore analyzed the data for the U.S. with respect to the above mentioned relationship and found that real wages are empirically also sticky downwards. For ease of reference, Figure 8 shows the relationship between real wages and output. To represent real wages, we use the annual growth rate of real average hourly earnings in the manufacturing sector and to represent output, we use as before the annual growth rate of the real gross domestic product. ${ }^{17}$ When having a look at the black trend time series, it becomes clearer that real wages are procyclical

\footnotetext{
${ }^{17}$ We only found a comparable time series for the U.S. that was available for the entire sample period. Concretely, we use the growth rate of the average nominal hourly earnings in the manufacturing sector. In order to obtain the real growth rate, we subtracted the inflation rate from the nominal growth rate.
} 


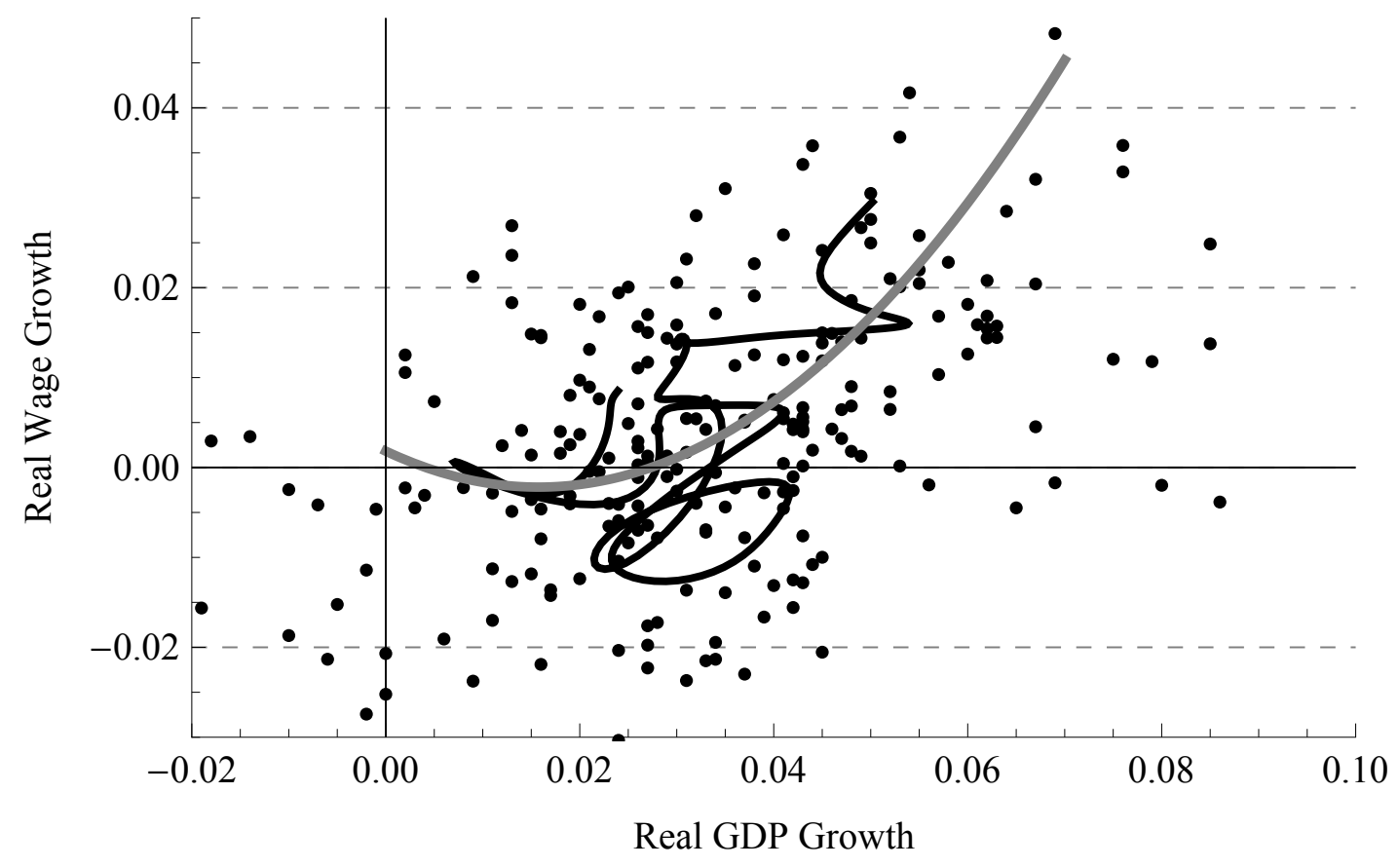

FiguRe 8: RELATIONSHiP BETWEEN REAL WAGES AND OUTPUT

and exhibit stickiness downward. This finding is even more evident, when having a look at the second-order polynomial trend, highlighted in gray.

\section{Conclusion}

We develop a dynamic general equilibrium model to analyze the relationship between monetary policy, money demand, and unemployment. We show that our model closely tracks money demand and succeeds in replicating the u-shaped relationship between nominal interest rates and unemployment. The reason behind this result is that our model implies a hump-shaped relationship between inflation and output if agents' risk aversion is sufficiently high. For low inflation rates, the type-I equilibrium exists and output is increasing in the inflation rate since young agents reduce their savings in order to increase their centralized market consumption which outweighs the consumption loss of old agents. Consequently, unemployment is decreasing in the nominal interest rate in this equilibrium. In contrast, for higher nominal interest rates the type-II equilibrium exists, where centralized market consumption is not affected by a change in inflation and all agents suffer the inflation tax. Therefore, output is decreasing in the inflation rate and unemployment increasing. 


\section{Appendix A: Analysis of the Model}

We analyze the model for the generation $t$ backwards. Hence, we first solve the old agents' problems in the goods market and in the centralized market in period $t+1$. Then we proceed to solve the young agents' problems in the goods market and in the centralized market in period $t$.

The goods market in period $t+1$

In period $t$, an agent of generation $t$ is old. The envelope condition for old agents is

$$
\frac{\partial W_{o}\left(\phi_{+1} m_{o,+1}\right)}{\partial m_{o,+1}}=\frac{1}{p_{+1}} v^{\prime}\left(q_{o,+1}\right)
$$

Since old agents spend all the money they have, the marginal utility of money for old agents equals the marginal gain of consuming more.

The centralized market in period $t+1$

The first order conditions for an old agent in terms of $m_{o,+1}$ and $x_{o,+1}$ are

$$
\frac{\partial W_{o}\left(\phi_{+1} m_{o,+1}\right)}{\partial m_{o, t+1}}=\frac{\phi_{+1}}{b} \quad \text { and } \quad U^{\prime}\left(x_{o,+1}\right)=\frac{1}{b}
$$

respectively. $\partial W_{o}\left(\phi_{+1} m_{o,+1}\right) / \partial m_{o, t+1}$ and $\phi_{+1} / b$ represent the marginal gain by saving for the goods market and the marginal cost of doing so. $U^{\prime}\left(x_{o, t+1}\right)$ and $1 / b$ represent the marginal gain of general goods consumption and the marginal cost of this consumption. By the nature of quasi-linear utility, the consumption in the centralized market and saving for the goods market are independent of the money holdings of old agents' entering the centralized market. The envelope condition for old agents in the centralized market is

$$
\frac{\partial V_{o}\left(\phi_{+1} \hat{m}_{o,+1}\right)}{\partial \hat{m}_{o,+1}}=\frac{\phi_{+1}}{b} .
$$

Hence, the marginal gain by bringing one more unit of money is equal to the ratio of the price of money in terms of general goods and the wage for old agents.

The goods market in period $t$

In period $t$, generation $t$ agents are young. Young agents can be either sellers or buyers in the goods market. If a price $p$ is strictly greater than $b /\left(\beta \phi_{+1}\right)$, then an equilibrium does not exist. Precisely, in the young seller's problem, the first order condition is positive, if $p>b /\left(\beta \phi_{+1}\right)$ :

$$
-1+\beta p \frac{\partial V_{o}\left(\phi_{+1} \hat{m}_{o,+1}\right)}{\partial \hat{m}_{o,+1}}=-1+\beta p \frac{\phi_{+1}}{b}>0 .
$$


Hence, it is optimal for young sellers to always sell more goods. On the other hand, if $p<$ $b /\left(\beta \phi_{+1}\right)$, then there is no monetary equilibrium, since it is optimal for sellers not to trade in the goods market. Therefore, the (monetary) equilibrium price is

$$
p=\frac{b}{\beta \phi_{+1}} .
$$

As a result, the interior first order condition for young buyers in the goods market is

$$
v^{\prime}\left(q_{y}\right)=\beta p \frac{\partial V_{o}\left(\phi_{+1} \hat{m}_{o,+1}\right)}{\partial \hat{m}_{o,+1}}=\beta p \frac{\phi_{+1}}{b} .
$$

Since the equilibrium price is $p=b /\left(\beta \phi_{+1}\right)$, we know that if the young buyers' budget constraint is not binding in equilibrium, then they can consume the efficient quantity in the goods market, $v^{\prime}\left(q_{y}\right)=1$. Otherwise, the marginal gain of the special goods consumption is greater than one, $v^{\prime}\left(q_{y}\right)>1$, in equilibrium. Moreover, the envelope condition for young agents in the goods market also depends on whether the budget constraint is binding or not. That is

$$
\frac{\partial W_{y}\left(\phi_{t} m_{y}\right)}{\partial m_{y}}=\delta \frac{v^{\prime}\left(q_{y}\right)}{p}+(1-\delta) \frac{1}{p}
$$

Hence, if the budget constraint is not binding in an equilibrium, then the envelope condition is

$$
\frac{\partial W_{y}\left(\phi_{t} m_{y}\right)}{\partial m_{y}}=\frac{1}{p}=\frac{\beta \phi_{+1}}{b}
$$

\section{The centralized market in period $t$}

The first order conditions for young agents in the centralized market are

$$
\begin{aligned}
& U^{\prime}\left(x_{y}\right)=\omega^{-1 \prime}\left(x_{y}+\phi m_{y}-T\right), \\
& \phi \omega^{-1 \prime}\left(x_{y}+\phi m_{y}-T\right)=\frac{\partial W_{y}\left(\phi m_{y}\right)}{\partial m_{y}} .
\end{aligned}
$$

Note, that since we have

$$
\omega^{-1 \prime}\left(x_{y}+\phi m_{y}-T\right)=\frac{1}{\omega^{\prime}\left(h_{y}\right)},
$$

the marginal gain of additional general goods consumption and the marginal value of saving more money when agents are young are inversely proportional to the marginal wage of young agents. 


\section{Appendix B: Proofs}

Derivation of (2). Using equations (1), (10), (11), and (12), we have

$$
v^{\prime}\left(q_{o,+1}\right)=1+i_{+1}
$$

By backward updating the period, we obtain (2).

Derivation of (3). It is immediate from (11).

Proof of Proposition 1. Derivation of (4). By using (12), (13), we can derive (4).

Derivation of (5). By using (1), (15), (16), (17), we can derive (5).

Proof of Proposition 2. Derivation of (6). In the type-II equilibrium, we have $\omega^{\prime}\left(h_{y}\right)=1$. Together with (1), (12), (14), (17), and (18), we can derive (6).

Derivation of (7). By using (16), (18) and the fact $\omega^{\prime}\left(h_{y}\right)=1$ in the type-II equilibrium, we can derive (7).

Proof of Proposition 3. The proof is followed by (16), (18), and the fact that $\omega^{\prime}\left(h_{y}\right) \in(b, 1)$ in the type-I equilibrium and $\omega^{\prime}\left(h_{y}\right)=1$ in the type-II equilibrium.

Proof of Proposition 4. By rearranging $\partial Y / \partial i$ for the type-I equilibrium in (9), we have

$$
\begin{aligned}
\frac{\partial Y}{\partial i} & =-\frac{1}{b(1+i)^{2} U^{\prime \prime}\left(x_{y}\right)}+b n q_{y}+b\left[1+\frac{v^{\prime}\left(q_{o}\right)}{q_{o} v^{\prime \prime}\left(q_{o}\right)}\right] q_{o} \\
& =-\frac{1}{b(1+i)^{2} U^{\prime \prime}\left(x_{y}\right)}+b n q_{y}+b\left(\frac{\alpha-1}{\alpha}\right) q_{o}
\end{aligned}
$$

Hence if $\alpha \geq 1$, then $\partial Y / \partial i>0$. Now consider the case in which $\alpha \in(0,1)$. In the type-I equilibrium, we have $q_{o}=v^{-1}(1+i), q_{y}=v^{\prime-1}(1)$, and $x_{y}=U^{\prime-1}[1 / b(1+i)]$ by $(2)$ and Proposition 1. Hence, $\partial Y / \partial i>0$ if and only if

$$
n v^{\prime-1}(1)-\frac{1}{[b(1+i)]^{2} U^{\prime \prime}\left(U^{\prime-1}[1 / b(1+i)]\right)}>\frac{1-\alpha}{\alpha} v^{\prime-1}(1+i) .
$$

Let

$$
\alpha_{1}(i):=\frac{n v^{\prime-1}(1)-1 /\left\{[b(1+i)]^{2} U^{\prime \prime}\left(U^{\prime-1}[1 / b(1+i)]\right)\right\}}{v^{\prime-1}(1+i)} .
$$

Then $\alpha_{1}(i)>n$. Moreover since $\alpha<1$, the inequality (19) is equivalent to

$$
\alpha>\frac{1}{1+\alpha_{1}(i)}
$$


Finally, the proof is immediately followed by defining

$$
\bar{\alpha}(i):=\frac{1}{1+\alpha_{1}(i)} .
$$

Proof of Proposition 5. From $\partial Y / \partial i$ for the type-II equilibrium in (9), we have

$$
\begin{aligned}
\frac{1}{b} \frac{\partial Y}{\partial i} & =n q_{y}+q_{o}+\frac{n v^{\prime}\left(q_{y}\right)+(1-n)}{v^{\prime \prime}\left(q_{y}\right)}+\frac{v^{\prime}\left(q_{o}\right)}{v^{\prime \prime}\left(q_{o}\right)} \\
& =\frac{(1-n)}{v^{\prime \prime}\left(q_{y}\right)}+\left[1+\frac{v^{\prime}\left(q_{y}\right)}{q_{y} v^{\prime \prime}\left(q_{y}\right)}\right] n q_{y}+\left[1+\frac{v^{\prime}\left(q_{o}\right)}{q_{o} v^{\prime \prime}\left(q_{o}\right)}\right] q_{o} \\
& =\frac{(1-n)}{v^{\prime \prime}\left(q_{y}\right)}+\frac{\alpha-1}{\alpha}\left(n q_{y}+q_{o}\right) .
\end{aligned}
$$

Therefore, if $\alpha \leq 1$ then $\partial Y / \partial i$, since $b>0$ and $v^{\prime \prime}\left(q_{y}\right)<0$.

\section{Appendix C: Data Sources}

The data we used for the calibration is downloadable from the FRED database of the Federal

Reserve Bank of St. Louis. For all time series, we use quarterly data. Table C.1 gives a brief overview of the data sources. 
TABle C.1: Data sources

\begin{tabular}{lll}
\hline \hline Description & Country & Identifier \\
\hline Unemployment rate & U.S. & UNRATE \\
3-month government bond yield & U.S. & TB3MS \\
Velocity of MZM & U.S. & MZMV \\
Consumer price index & U.S. & CPIAUCSL_PC1 \\
Real GDP growth & U.S. & A191RO1Q156NBEA \\
Nominal wage growth & U.S. & CES3000000008_PC1 \\
Unemployment rate & Canada & LRUNTTTTCAQ156S \\
3-month government bond yield & Canada & IR3TIB01CAQ156N \\
M1 & Canada & MANMM101CAQ189S \\
Gross domestic product & Canada & CANGDPNQDSMEI \\
Consumer price index & Canada & CPGRLE01CAQ659N \\
Real GDP growth & Canada & CANGDPRQPSMEI \\
Unemployment rate & U.K. & AURUKM \\
3-month government bond yield & U.K. & IR3TTS01GBM156N \\
M1 & U.K. & MSM1UKQ \\
Gross domestic product & U.K. & UKNGDP \\
Real GDP growth & U.K. & RGDPMPUKQ_PC1 \\
\hline
\end{tabular}

\section{References}

Ball, L., Leigh, D., and Loungani, P., 2017. "Okun's Law: Fit at 50?", Journal of Money, Credit and Banking, 49, 1413-1441.

Bhattacharyaa, J., Haslag, J., Russell, S., 2005. "The Role of Money in Two Alternative Models: When is the Friedman Rule Optimal, and Why?", Journal of Monetary Economics, 52, 14011433.

Berentsen, A., Camera, G., and Waller, C., 2007a. "Money, Credit and Banking", Journal of Economic Theory, 135, 171-195.

Berentsen, A., Rocheteau, G., and Shi, S., 2007b. "Friedman Meets Hosios: Efficiency in Search Models of Money", The Economic Journal, 117, 174-195.

Berentsen, A., Huber, S., and Marchesiani, A., 2018. "Limited Commitment and the Demand for Money", The Economic Journal, 128 (610), 1128-1156.

Berentsen, A., Menzio, G., and Wright, R., 2011. "Inflation and Unemployment in the Long Run", American Economic Review, 101, 371-398. 
Bethune, Z., Rocheteau, G., and Rupert, P., 2015. "Unemployment and Household Unsecured Debt", Review of Economic Dynamics, 18, 77-100.

Branch, W. A., Petrosky-Nadeau, N., and Rocheteau, G., 2016. "Financial Frictions, the Housing Market, and Unemployment", Journal of Economic Theory, 164, 101-135.

Freeman, S., 1993. "Resolving Differences Over the Optimal Quantity of Money", Journal of Money, Credit, and Banking, 25, 801-811.

Guisinger, A. Y., Hernandez-Murillo, R., Owyang, M. T., and Sinclair, T. M., 2017. "A StateLevel Analysis of Okun's Law", Regional Science and Urban Economics, 68, 239-248.

Huangfu, S. X., 2018. "The Effects of Inflation on Market Participation and Search Intensity", Economic Record, 94, 25-38.

Huber, S., and Kim, J., 2018. "An Overlapping Generations Model for Monetary Policy Analysis", Working Paper.

Knotek, E. S., 2007. "How Useful is Okun's Law?", Economic Review, Federal Reserve Bank of Kansas City, 73-103.

Kiyotaki, N., and Wright R., 1989. "On Money as a Medium of Exchange", Journal of Political Economy, 97, 927-954.

Lagos, R. and Rocheteau, G., 2005. "Inflation, Output, and Welfare", International Economic Review, 46, 495-522.

Lagos, R., Rocheteau, G., and Wright, R., 2017. "Liquidity: A New Monetarist Perspective", Journal of Economic Literature, 55, 371-440.

Lagos, R., and Wright, R., 2005. "A Unified Framework for Monetary Theory and Policy Evaluation", Journal of Political Economy, 113, 463-484.

Lucas, R. E., 1972. "Expectations and the Neutrality of Money", Journal of Economic Theory, $4,103-124$.

Lucas, R. E., 2000. "Inflation and Welfare", Econometrica, 68, 247-274.

Lucas, R. E., and Nicolini, J. P., 2015. "On the Stability of Money Demand", Journal of Monetary Economics, 73, 48-65. 
Maeda, Y., 1991. "Fiat Money in a Pairwise-Trading, Multi-Good, Overlapping Generations Model", Journal of Economic Theory, 54, 84-97.

Meyer, B., and Tasci, M., 2012. "An Unstable Okun's Law, Not the Best Rule of Thumb", Economic Commentary, Federal Reserve Bank of Cleveland.

Mortensen, D., Pissarides, C., 1994. "Job Creation and Job Destruction in the Theory of Unemployment", Review of Economic Studies, 61, 397-415.

Okun, A. M., 1962. "Potential GNP: Its Measurement and Significance", Proceedings of the Business and Economics Statistics Section, American Statistical Association, 98-104.

Owyang, M. T., Sekhposyan, T., and Vermann, K., 2013. "Output and Unemployment: How Do They Relate Today?", The Regional Economist, Federal Reserve Bank of St. Louis.

Phillips, A. W., 1958. "The Relation Between Unemployment and the Rate of Change of Money Wage Rates in the United Kingdom, 1861-1957", Economica, 25, 283-299.

Rocheteau, G., and Lopez, A. R., 2014. "Liquidity Provision, Interest Rates, and Unemployment", Journal of Monetary Economics, 65, 80-101.

Rocheteau, G., Rupert, P., Wright, R., 2007. "Inflation and Unemployment in General Equilibrium", Scandinavian Journal of Economics, 109, 837-855.

Rocheteau, G., Weill, P. O., Wong, T. N., 2018. "An Heterogeneous-Agent New-Monetarist Model with an Application to Unemployment", Working Paper.

Rocheteau, G., and Wright, R., 2005. "Money in Search Equilibrium, in Competitive Equilibrium, and in Competitive Search Equilibrium", Econometrica, 73, 175-202.

Rocheteau, G., and Wright, R., 2009. "Inflation and Welfare in Models with Trading Frictions", Monetary Policy in Low Inflation Economies, ed. by Ed Nosal and Dave Altig, Cambridge University Press.

Rogerson, R., 1988. "Indivisible Labor, Lotteries and Equilibrium", Journal of Monetary Economics, 21, 3-16.

Rogerson, R., Shimer, R., and Wright, R., 2005. "Search-Theoretic Models of the Labor Market: A Survey", Journal of Economic Literature, 43, 959-988. 
Samuelson, P. A., 1958. "An Exact Consumption-Loan Model of Interest With or Without the Social Contrivance of Money", Journal of Political Economy, 66, 467-482.

Shi, S., 1998. "Search for a Monetary Propagation Mechanism", Journal of Economic Theory, $81,314-352$.

Shi, S., 2006. "Viewpoint: A Microfoundation of Monetary Economics", Canadian Journal of Economics, 39, 643-688.

Wallace, N., 1980. "The Overlapping Generations Model of Fiat Money", Models of Monetary Economies, ed. by Neil Wallace and John Kareken, Federal Reserve Bank of Minneapolis, $49-82$.

Waller, C. J., 2015. "Microfoundations of Money: Why They Matter", Review, Federal Reserve Bank of St. Louis, 97, 289-301.

Wen, Y., and Chen, M., 2012. "Okun's Law: A Meaningful Guide for Monetary Policy?", Economic Synopses, Federal Reserve Bank of St. Louis.

Wright, R., 2005. "Introduction to Models of Monetary Economies II: The Next Generation", International Economic Review, 46, 305-316.

Zhu, T., 2008. "An Overlapping-Generations Model with Search", Journal of Economic Theory, $142,318-331$. 